\title{
Guardia Campesina del Catatumbo, (Asociación Campesina del Catatumbo ASCAMCAT). Entre la autoprotección, el empoderamiento y la construcción territorial
}

\section{Catatumbo's Campesino Guard, (Asociación Campesina del Catatumbo ASCAMCAT). Between self-protection, empowerment and territorial construction}

\author{
José Manuel Alba Maldonado \\ Universidad Francisco de Paula Santander \\ jmalbam@ufpso.edu.co
}

\section{Javier Alonso Santiago Velásquez}

Universidad Nacional Abierta y a Distancia de Colombia (UNAD)

javisanvela@gmail.com

\section{Edidvanidt Jácome Garzón iD}

Universidad Nacional Abierta y a Distancia de Colombia (UNAD

edijagar@gmail.com

\section{Resumen}

El presente artículo es resultado de un trabajo de investigación social, centrado en identificar cómo a partir de procesos de autoprotección como la Guardia Campesina del Catatumbo de la Asociación Campesina del Catatumbo (ASCAMCAT), se han generado procesos de empoderamiento y construcción del territorio. El diseño metodológico se desarrolla dentro de un paradigma cualitativo y enfoque histórico hermenéutico, usando herramientas de recolección de información como la observación directa, estudios de caso, historia de vida, reconstrucción de memoria histórica. Entre los principales resultados se puede mencionar que la Guardia Campesina surge como una acción de autoprotección debido a la vulnerabilidad que presentan las comunidades rurales en la región del Catatumbo, generando empoderamiento del territorio y procesos de construcción territorial.

Palabras clave: Asociación Campesina del Catatumbo, territorio, organización, empoderamiento, autoprotección.

\begin{abstract}
This article is the result of a social research work, focused on identifying how self-protection processes such as the Catatumbo's Campesino Guard of Asociación Campesina del Catatumbo (ASCAMCAT) have generated processes of empowerment and construction of the territory. The methodological design is developed within a qualitative paradigm and hermeneutical historical approach, using information gathering tools, such as direct observation, case studies, life history, reconstruction of historical memory. Among the main results it can be mentioned that the Peasant Guard emerges as a selfprotection action due to the vulnerability of rural communities in the Catatumbo region, generated territory empowerment and territorial construction process.


Keywords: Asociación Campesina del Catatumbo (ASCAMCAT), Territory, Region, Organization.Artículo: Recibido el 10 de junio de 2019 y aprobado el 29 de enero de 2019.

Articulo: Recibido el 18 de diciembre de 2019 y aprobado el 28 de enero de 2020

\section{Cómo citar este artículo:}

J.M. Alba-Maldonado, J.A. Santiago Velásquez \& Edidvanidt Jácome Garzón. (2020). Guardia Campesina del Catatumbo, (Asociación Campesina del Catatumbo ASCAMCAT). Entre la autoprotección, el empoderamiento y la construcción territorial. Reflexión Política 22(44), pp. 70-85 . doi: 10.29375/01240781.3805

\section{Introducción}

Dentro de las regiones azotadas por el conflicto armado, han surgido iniciativas organizativas de las comunidades que intentan salvaguardar su integridad, lo cual, a su vez, lleva a que se generen procesos de empoderamiento en sus territorios, en los que se busca tener decisión sobre sus proyectos como comunidad, disposiciones sobre sus recursos naturales y demostrar capacidades propositivas en el ordenamiento de su región. Desde estas relaciones surgen construcciones de territorio y territorialidades que se dinamizan frente a las dinámicas entre las sociedades rurales y el ambiente.

Los antecedentes más cercanos al proceso campesino son la Guardia Indígena y la Guardia Cimarrona; estas se ubican en zonas reconocidas por el Gobierno con autonomía por pertenecer a grupos étnicos y en donde hay autoridad territorial. Las guardias Indígena y Cimarrona han tenido mayor visibilidad, debido a su antigüedad y protagonismo en diferentes escenarios como la región del Cauca y Chocó en el marco de diferentes movilizaciones en defensa del territorio; sin embargo, no ha ocurrido lo mismo frente al caso campesino, debido a que este es un fenómeno de inicios de la segunda década del siglo XXI.

La Guardia Campesina del Catatumbo fue creada en diciembre de 2014 como propuesta de autoprotección en zonas de conflicto armado, en lo que constituye un referente a nivel nacional e internacional. Sin embargo, esta estructura, que pertenece a la Asociación Campesina del Catatumbo (ASCAMCAT), no se ha estudiado todavía desde la academia; en contraste, se han generado procesos de estigmatización por parte de algunos partidos políticos, Fuerza Pública y gremios económicos agroempresariales e inversionistas interesados en la riqueza mineroenergética del Catatumbo. Por tal razón, es necesario hacer un análisis de sus procesos internos, su historia, su conformación y cómo estos hacen parte de propuestas de las comunidades campesinas que buscan empoderarse de su territorio y hacer un llamado al Estado para ser reconocidos como sujetos de derechos y con capacidades políticas, como respuesta a las situaciones vividas en el territorio, la presencia histórica de la subversión, la llegada del paramilitarismo, el aumento de los cultivos de coca y la pobreza que vive el campesinado.

El objetivo de la investigación se centró en identificar cómo a partir de procesos de autoprotección como la Guardia Campesina del Catatumbo de la ASCAMCAT, se ha generado empoderamiento y construcción de territorio, en respuesta al abandono estatal y la presencia histórica del conflicto armado en la región.

\section{Referentes teóricos}

Para el desarrollo del trabajo se abordaron conceptos clave desde posturas teóricas acordes con la visión de defensa del territorio y empoderamiento de las comunidades campesinas.

\section{El campesino}

Establecer una definición única para abordar la cuestión del campesinado sería negar la complejidad de su ser. Sin embargo, existen elementos conceptuales y teóricos que dan aproximaciones a su entendimiento como un sujeto cultural capaz de autodeterminarse, construir conocimiento y generar sus propias condiciones de vida. 
Un elemento importante en la construcción del concepto de campesino es la economía familiar. Chayanov (citado en Sevilla y González, 2004) señala que:

La economía familiar no es simplemente la supervivencia de los débiles por medio de su empobrecimiento que sirve a beneficios de otros, sino también la utilización de algunas de las características de la agricultura y de la vida social rural que pueden proporcionar ventajas a las economías no capitalistas sobre las formas de producción capitalistas en un mundo capitalista. (p. 28)

Ahora bien, esta forma de producción familiar ha contribuido a la generación de un proceso cultural campesino, que se enmarca no solo en su producción, sino también en la relación con la tierra, la construcción territorial y su forma organizacional.

Guesada (2013), en su libro Derecho a la consulta previa para comunidades campesinas, señala que:

Existe una relación entre el campesino como un sujeto económico y el campesino como sujeto cultural, señalando que el campesino tiene una particular forma de concebir su actividad productiva familiar, que lo diferencia del modo capitalista de producción. La producción familiar se convierte en un aspecto importante en la cultura campesina ligado a la cultura, y hace parte fundamental del desarrollo de la vida productiva y social de las comunidades campesinas. (p. 32)

De esta manera, se puede decir que el campesino se constituye como un sujeto cultural, como lo refieren Salgado y Prada, quienes describen cómo los campesinos tienen una mirada de manera diferenciada en las relaciones económicas, sociales y políticas, y reaccionan con justa razón cuando piden que se les reconozca la condición de miembros de la sociedad (Ortiz Valencia, 2013). Estas relaciones dinámicas hacen que construyan su ser cultural, igual que los indígenas y las comunidades afro, que establecieron formas de vida propia y han logrado persistir hasta el momento.

Kroeber caracteriza la sociedad campesina como una "forma de organización con estructuras rurales a pesar de vivir en relación con los mercados de las ciudades, con unidades locales que conservan su vieja identidad, integración y apego a la tierra y a los cultivos" (Kroeber, 1948, p. 284).

Frente a la conceptualización del campesino, Shanin (1979) menciona que: "día tras día los campesinos hacen suspirar a los economistas, sudar a los políticos y maldecir a los estrategas, al derrotar sus planes y profecías por todo el mundo" (p. 236). El análisis de esta frase da luces para entender al campesino como un ser histórico, que forja identidades territoriales, roles sociopolíticos que cambian históricamente, como lo es la Guardia Campesina, en la cual, por medio de acciones de autoprotección responden a unas dinámicas políticoeconómicas como lo es el modelo neoextractivista de los recursos naturales.

\section{El campesino en Colombia}

El campesino colombiano ha estado sometido a una presión constante, debido a que la tierra tiene un fuerte vínculo de posesión en donde intervienen el poder político, las élites locales y nacionales, inversiones internacionales y actores armados, convirtiéndose en foco de fenómenos de ilegalidad cuyo acaparamiento ha generado violencia de manera sistemática. De esta forma, el campesinado ha sido golpeado por acciones coercitivas, el miedo, la intimidación, el despojo violento de sus tierras, el asesinato de sus líderes y el desconocimiento de los derechos humanos (Machado, 2017). El Catatumbo no es ajeno a estas dinámicas, para 1930 se llevaron a cabo explotaciones petroleras y se expulsó a los indígenas Barí a la zona norte del departamento. Para mediados del siglo XX se registró la llegada de colonos en búsqueda de tierra y se amplió la frontera agraria. Entre 1970 y 2004, el Catatumbo fue un escenario de confrontación armada entre guerrilla, Estado y posteriormente, paramilitarismo. A este panorama hay que agregarle un alto índice de necesidades básicas insatisfechas y la presencia de cultivos de coca con un aumento exponencial año a año.

Estas dinámicas son el resultado de políticas económicas y sociales que no han generado un beneficio a los sectores rurales y han negado la asistencia técnica, con cifras que demuestran que lo rural en Colombia no ha sido un sector de importancia para las políticas gubernamentales. A pesar de que la agricultura es la principal fuente de trabajo para las zonas rurales, es también el sector que tiene menor remuneración. Con respecto a la 
afiliación de salud, el sector rural está 1,6\% por debajo del sector urbano. Otro aspecto claro para analizar el abandono del sector rural en Colombia es la afiliación a pensiones, en la cual el sector rural está 29 puntos por debajo de las zonas urbanas (Ministerio de Agricultura, 2016).

Durante el siglo $\mathrm{XX}$, ha existido una deuda histórica y social del Estado colombiano y la Nación con la cultura campesina y sus modelos de producción, fruto de fenómenos políticos y económicos en donde se ha reducido su importancia. Así las cosas, la principal deuda que tiene la sociedad con el campesinado es reconocerlo como un productor, que contribuye sustancialmente a la alimentación, agroindustria y exportaciones del país. Es necesario concebirlo como un ciudadano que tiene plenos derechos, que debe gozar de una buena alimentación, de vivienda digna, de educación de calidad, de salud y sobre todo, reconocerlo como sujeto activo y partícipe de la producción cultural del país (Forero, 2010).

\section{Autoprotección y empoderamiento territorial en el Catatumbo}

Las confrontaciones, persecuciones, despojo, violencia, estigmatizaciones por parte de las insurgencias del paramilitarismo, las Fuerzas Militares, empresas multinacionales y nacionales interesados en los recursos mineroenergéticos de la región, generaron reacomodos en las zonas rurales, en donde las identidades, recursos naturales, memoria y cultura, llevaron al campesinado y las sociedades rurales a concebir nuevas propuestas organizativas. La autodefensa de su "ser", "quehacer", y "querer ser", tuvo como consecuencia la germinación de propuestas orgánicas a través de movimientos sociales que se articularon con su espacio geográfico para la construcción de territorio, así surgieron acciones de empoderamiento y autoprotección frente a los actores violentos y las políticas estatales.

Ante las ausencias diferenciales del Estado (centrado en la presencia de las Fuerzas Militares y ausencia del Estado Social del Derecho), la escasa voluntad y la poca eficiencia en la protección colectiva a las comunidades rurales, se han desarrollado medidas de autoprotección colectiva con un enfoque holístico que tienen como objetivo proporcionar seguridad a los colectivos y sus líderes. Estas formas de autoprotección están intimamente ligadas a la construcción de paz, ya que todos los modelos responden a la necesidad de neutralizar la violencia de la que han sido víctimas. Las medidas de autoprotección no son exclusivas de la protección física, también hacen referencia a las múltiples relaciones que se dan en el territorio, como la permanencia, seguridad política, económica y del medio ambiente, así como bienestar psicosocial, espiritual y cultural. Es por esta razón que en la autoprotección se incorpora al individuo, la comunidad y su territorio (ABColombia, Aid, Oxfam, SCIAF y Trócaire, 2016).

Los mecanismos de autoprotección de las comunidades rurales inmersas en contextos del conflicto armado, se expresan desde opciones no violentas y pragmáticas para la construcción de paz. De modo que las resistencias civiles son resistencias para la paz (Delgado, 2009), como las realizadas por la Guardia Indígena en el departamento del Cauca a partir de acciones en defensa del territorio y de su cultura a través de la "minga" organizada desde 2004 por medio de marchas hasta la ciudad de Bogotá, bloqueo de vías y debate con los presidentes de la época. De igual manera, las acciones de la Guardia Cimarrona respecto a la organización territorial para contrarrestar la minería ilegal en el departamento del Chocó, son ejemplo de autoprotección en Colombia.

Se podría decir que la autoprotección es una iniciativa de paz desde la base, en donde la población ejerce un papel activo, debido a que es ella la que soporta el impacto directo de la violencia, especialmente del conflicto armado o de la corrupción administrativa. La autoprotección y autonomía están ligadas al territorio y hacen parte de la profundización de la democracia (Delgado, 2002).

La autoprotección tiene su origen en las ineficiencias del Estado, que son respondidas por las comunidades organizadas en un espacio geográfico. Dichas comunidades no solo se limitan a salvaguardar la vida de los líderes o las personas que las integran, la protección se extiende a las relaciones entre las sociedades y el territorio. Por tal motivo, las acciones van ligadas a la defensa de la vida que está atada al ambiente, la cultura, la tierra y la memoria. Un factor determinante según los trabajos de Delgado (2002), es que estas acciones de autoprotección responden a las diferentes acciones violentas (por parte de actores armados, intereses económicos privados o del mismo Estado) con gestiones de carácter no violenta, ya que la 
autoprotección tiene como fin fundamental la construcción de la paz en el territorio.

Los movimientos rurales con base territorial juegan un papel fundamental en la autoprotección, ya que son un actor organizado y responden a través de sus propuestas y ordenamiento territorial a las formas liberales, estatales y capitalistas que pretenden reorganizar el territorio, desde intereses particulares, algunas veces de manera violenta. De esta manera, la forma de organización de los movimientos rurales controvierte el orden epistémico de la política moderna (Escobar, 2011).

Los mecanismos de autoprotección son respuesta a las confrontaciones de lo que Mari stella Svampa denomina neoextractivismo, caracterizándolo como un modelo de desarrollo basado en la sobreexplotación de bienes naturales no renovables, que amplía las fronteras de explotación a territorios que antes habian sido subvalorados. Existe una etapa de multiplicación de proyectos extractivos, esto incrementó exponencialmente los megaproyectos extractivos, aumentando las conflictividades territoriales, la criminalización de las luchas socioambientales y la violencia estatal y paraestatal (Svampa, 2018). Lo anterior es clave para entender las dinámicas del Catatumbo, en donde se adelantan estudios para explotación de recursos mineroenergéticos, y expansión del cultivo de palma africana dentro de un modelo agroexportador y agroempresarial.

El profesor Mancano (2010) señala que el territorio es "el espacio apropiado por una determinada relación social que lo produce y mantiene a partir de una forma de poder. Ese poder [...] es concebido por la receptividad. El territorio es, al mismo tiempo, una convención y una confrontación" (p. 10). De esta forma, el territorio en el Catatumbo es un espacio apropiado y construido por las comunidades campesinas e indígenas, quienes a partir de sus formas propias de gobierno y justicia comunitaria han logrado defender sus intereses de los proyectos económicos.

Ahora bien, el empoderamiento territorial de las comunidades campesinas se da en un inicio desde las Juntas de Acción Comunal (JAC). Según Sánchez Otero (2012), las JAC son una "organización cívica, social y comunitaria de gestión social, sin ánimo de lucro, de naturaleza solidaria, con personería jurídica y patrimonio propio, integrada voluntariamente por los residentes de un lugar que aúnan esfuerzos y recursos para procurar un desarrollo integral, sostenible y sustentable con fundamento en el ejercicio de la democracia participativa" (p. 67). Son estas quienes establecen el orden social, productivo y ambiental en los territorios campesinos. Las JAC ejercen la máxima autoridad, reglamentando los usos del territorio, y estableciendo normas de convivencia.

Este empoderamiento lo potencializa la pobreza en la que viven sus habitantes: "se debe a la débil presencia del Estado y los insuficientes recursos invertidos en suplir las necesidades más sentidas de los pobladores" (Valdés Correa, 2018). Esto lleva a que las comunidades realicen procesos de empoderamiento como arreglo de vías, generación de estructuras de justicia comunal, organizaciones comunitarias y en las últimas estructuras de autoprotección, como una forma de resistir en el territorio y defenderlo.

Las organizaciones sociales juegan entonces un papel fundamental en la defensa y empoderamiento territorial, estas han abanderado propuestas de su ordenamiento, como lo son las Zonas de Reserva Campesina (ZRC):

Las Zonas de Reserva Campesina se advierten como una figura organizativa del territorio que le permitiría al campesinado colombiano delimitar, asignar y aprovechar el territorio de una manera organizada, planificada y participativa, reivindicando así su derecho a la propiedad rural $\mathrm{y}$ fortaleciendo también su proyecto de vida en el medio que tradicionalmente conoce (Reyes Bohórquez, 2011).

\section{El Catatumbo y la asociación campesina}

Catatumbo se relaciona con un concepto geográfico. El PNUD lo describe como una región ubicada en el departamento de Norte de Santander al nororiente de Colombia con una extensión de 10.089 kilómetros cuadrados, conformada por once municipios: Tibú, El Tarra, Sardinata, El Carmen, Convención y Teorama, San Calixto, Hacarí, La Playa, Ocaña y Bucarasica (PNUD, 2014). Sin embargo, el Catatumbo también se debe entender desde las relaciones culturales, históricas, económicas, sociales y ambientales que han construido y desarrollando empoderamiento territorial por parte de las comunidades campesinas.

Estos procesos se dan dentro del abandono estatal que surge a partir de 1950 con la llegada de los primeros colonos y la creación de las primeras Juntas de Acción Comunal que tenían como 
función el ordenamiento territorial, la creación e implementación de justicia comunitaria y normas de convivencia en la región.

Como lo diría Delgado (2003), "La geografía no debe hacer del espacio un fetiche, cuyo estudio pueda reducirse a la geometría de sus formas, sin tener en cuenta las condiciones históricas que lo generan” (p. 80). Es por esto que el Catatumbo es entonces para el campesinado el territorio y el espacio construido poco a poco por las comunidades con el fin de realizar su vida en confluencia con la naturaleza.

La construcción de la región del Catatumbo ha estado sumergida en un abandono diferencial del Estado, obligando a los campesinos a organizarse y a construir sus formas comunitarias de poder, estableciendo características territoriales como la propuesta de Zona de Reserva Campesina, que les ha permitido convivir y mantener la defensa de sus vidas y la permanencia en el territorio como eje central de la organización campesina. Es por lo anterior que surgen en la región organizaciones sociales como la ASCAMCAT, como forma de defensa y desarrollo territorial.

ASCAMCAT, es una organización de campesinos y campesinas de la región, que se conformó en el departamento de Norte de Santander por habitantes de la zona rural de los municipios de Hacarí, Tibú, El Carmen, San Calixto, El Tarra, Teorama y Convención en el año 2005, en el marco del retorno que realizan los campesinos desplazados a su región luego de la desmovilización del paramilitarismo.

ASCAMCAT surge como una propuesta asociativa de reconstrucción del tejido social con el propósito de generar condiciones de vida digna para los catatumberos, quienes se han integrado en torno a la defensa del territorio, el respeto a las comunidades indígenas; la no fumigación de los cultivos de uso ilícito y la erradicación de los factores socioeconómicos que dieron origen a la siembra; la defensa de los bienes ambientales y naturales; el rescate de tradiciones culturales; la participación en la toma de decisiones; el respeto a la vida; $y$, en general, la defensa de los derechos fundamentales de los habitantes en el Catatumbo (ASCAMCAT y INCODER, 2012, p. 27).

Esta iniciativa surge debido a que en ese año, el Gobierno nacional, en cabeza de Álvaro Uribe Vélez, impulsó el Plan Colombia que traía consigo desplazamiento, erradicación violenta de cultivos ilícitos, robos de tierras y de ganado, desapariciones y masacres (ASCAMCAT y INCODER, 2012), por lo que la comunidad decidió declararse en refugio humanitario en la vereda de San Juancito del municipio de Teorama, y se dio así la creación y conformación de la asociación.

Fue en el 2009, cuando 300 campesinos fueron desplazados del corregimiento de San Juancito en el municipio de Teorama. Esto generó que la asociación instalara un campamento de refugio humanitario para acompañar a las personas que habían sido sacados de sus tierras (La Opinión, 2019).

Las movilizaciones en el territorio llevaron a la creación de iniciativas como la Mesa de Interlocución y Acuerdo 2009, donde se logró que el campesinado presentara la problemática del Catatumbo ante el gobierno de Álvaro Uribe Vélez y continuara trabajando en el pliego de peticiones que exigía el campesinado para el Catatumbo (Agencia Prensa Rural, 2018).

Para el año 2012 con base en la Ley 160 de 1994, buscando iniciar un proceso de reconocimiento de la propuesta de Zona de Reserva Campesina del Catatumbo ZRC-C que al día de hoy continúa sin tener aprobación por parte del Gobierno nacional (Agencia Prensa Rural, 2018).

Dentro de estas iniciativas también surgió en la ASCAMCAT la Guardia Campesina, creada después de la constituyente regional del Catatumbo, el 5 y 6 de diciembre de 2014, donde los campesinos exigieron la creación de un órgano de autoprotección (Agencia Prensa Rural, 2018).

\section{Camino metodológico}

El diseño metodológico de la investigación se centró en un paradigma cualitativo, ubicado en un enfoque histórico hermenéutico, en la medida en que se trata de un trabajo que abordó la reconstrucción de memoria de la Guardia Campesina del Catatumbo y un análisis de los procesos internos de las comunidades a nivel de organización, frente a los procesos de autoprotección, territorio y empoderamiento territorial.

Dentro de las diversas herramientas de recolección de información, se utilizó la observación directa en algunos encuentros y asambleas realizadas en elaño 2017 y 2018, comolos encuentros "Diálogos útiles para la paz" en el municipio de San Calixto, "Audiencia popular regional de ASCAMCAT" 
en San Calixto, y "Asamblea comunitaria del Plan Nacional Integral de sustitución de cultivos de uso ilícito" en Tibú. Se recuperó la historia de vida, a través de entrevistas semiestructuradas directas, de miembros de ASCAMCAT y líderes como Elizabeth Pabón, Wilmer Tellez y Yonni Abril; además de entrevistas con defensores de derechos humanos cercanos a los procesos del Catatumbo. En lo que tiene que ver con la reconstrucción de memoria histórica, se recopiló información sobre los procesos de su creación, organización, defensa del territorio y procesos evolutivos; por último, se hizo un análisis documental de algunos recursos bibliográficos de la asociación que muestran los lineamientos de la Guardia.

Figura 1. Guardia campesino, municipio de San Calixto, 2018.

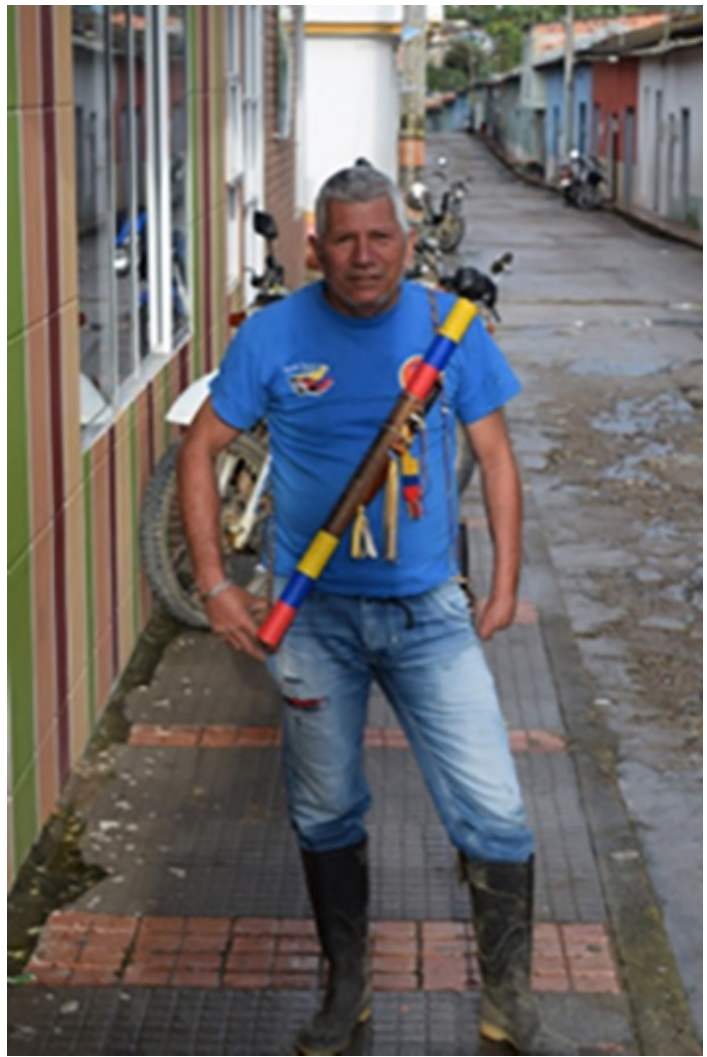

Fuente: Elaboración propia.

\section{Resultados y discusión}

\section{Génesis de la Guardia Campesina}

El Catatumbo es quizás una de las regiones con mayores conflictividades del país. Fue escenario de procesos de colonización tardía en el siglo $\mathrm{XX}$, con los inicios de la explotación petrolera en 1930 y búsqueda de tierra a mediados del siglo. A esto se le suma la presencia histórica de grupos subversivos que llegaron para los años setenta y ochenta, incursión de cultivos de uso ilícitos para los años noventa y embestida paramilitar en el año 1999. Además de esto, hay que agregar que es una zona multicultural con presencia de campesinos colonos provenientes de varias regiones del país e indígenas Motilón Barí (Avellaneda, 1998).

El Catatumbo es una región que posee múltiples conflictividades, esto se debe en gran medida por la disputa en torno a la apropiación de recursos naturales, riqueza mineral, natural e hídrica. Dichas conflictividades han generado modelos de vida y de resistencia por parte de las comunidades campesinas e indígenas.

La crudeza del conflicto armado tiene como consecuencia un arraigo muy fuerte del campesinado a su tierra. A pesar de que han sido víctimas de ciclos de violencia, desplazamiento y estigmatización, el hombre y la mujer catatumbera permanecen en el territorio.

En el Catatumbo, el vacío del Estado hace que el ejercicio organizativo propio de los campesinos busque la construcción del poder desde las bases. En este sentido, son muy importantes los movimientos sociales y esto permite hacer un ejercicio de control territorial y pensar sus derechos, como respuesta a la violación masiva de derechos humanos.

Wilmer Téllez, coordinador de la Guardia Campesina, y Elizabeth Pabón, presidenta de ASCAMCAT, mencionan que la región de Catatumbo siempre ha sido de interés para fuerzas externas (Pabón, 2018): "el gobierno, por ejemplo, llegaba de manera violenta a erradicar, imponer su fuerza, entonces se generan muchos desplazamientos, entonces se decide no salir del territorio sino hacer resistencia. La guardia fue una protección a los campesinos" (Téllez, 2018).

Los orígenes de la Guardia Campesina se remontan a la ZRC en el municipio de Corinto en el Cauca, en donde inspiradas en los modelos de la Guardia Indígena, las comunidades propusieron que se estudiara la viabilidad para su creación en el Catatumbo, debido a que allí también estaba concentrado el conflicto armado, desplazamiento, presencia del cultivo de coca y altos niveles de pobreza (Quesada, 2018). Es entonces en estos escenarios de disputa donde la Guardia Campesina surge como un mecanismo de autoprotección en el marco de la ZRC-C (Silla Santandereana, 2018). 
Figura 2. Entrevista presidenta de ASCAMCAT, Caño Indio municipio de Tibú, 2018.

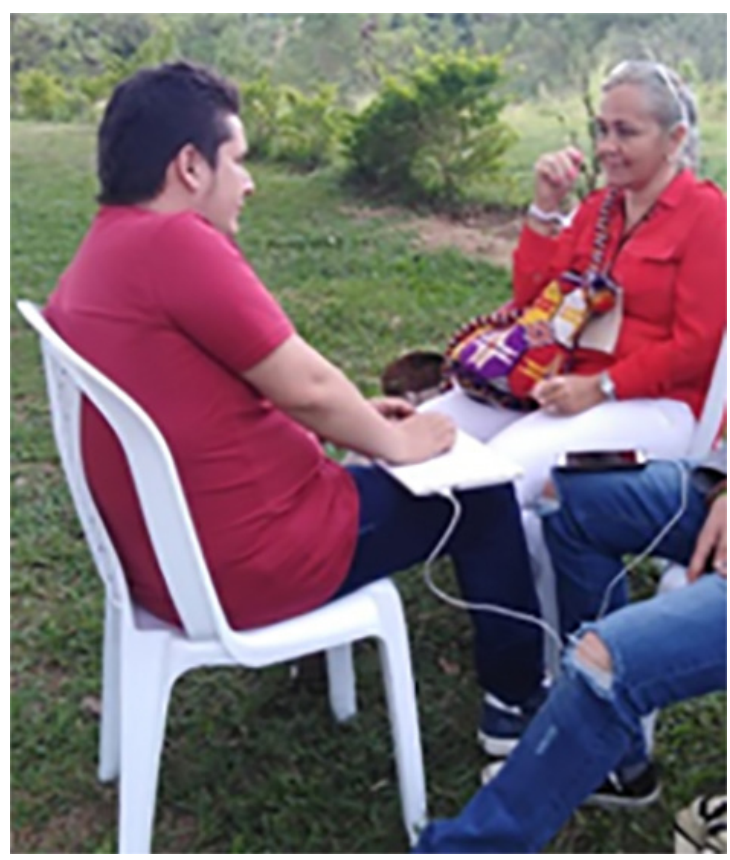

Fuente: Elaboración propia.

Para el 2013 hay un antecedente en la región del Catatumbo, en la vereda Miramontes, donde grupos de jóvenes raspadores de hoja de coca que se denominaban Los Bolilleros (debido al uso de un bolillo artesanal), empezaron hacer oposición a los erradicadores y eso condujo a confrontaciones con la fuerza pública (Abril, 2018). Esta confrontación inició por la detención de campesinos raspadores de hoja de coca que fueron presentados posteriormente como guerrilleros.

El pasado día 24 de Noviembre de 2013 alrededor de las 9:00 am, efectivos del Cuerpo Técnico de Investigación - CTI junto con aproximadamente cuarenta soldados del batallón Mecanizado General Maza, adelantaron un operativo en el que se vieron fueron detenidos varios campesinos de la vereda Miramontes, municipio de Tibú.... A los campesinos los detuvieron mientras realizaban sus actividades diarias (Prensa Rural, 2013).

Posteriormente, cuando empieza el paro campesino en junio de 2013, los campesinos se ven obligados a salir a las calles, y los bolilleros toman un papel protagónico debido a que eran ellos los que venían con mayor tiempo en resistencia, cerca de dos meses enfrentándose a los escuadrones de erradicación y a la fuerza pública en los cultivos (Quesada, 2018).
Los 53 días de paro cobraron la vida de cuatro civiles en confusos hechos (Caracol Radio, 2013), este sería el inicio de la Guardia Campesina. El 23 de junio fueron asesinados dos campesinos cuando la movilización quería tomarse el aeropuerto de Ocaña, y el 25 de junio murieron otros dos campesinos y hubo tres heridos por disparos de bala provenientes de la Fuerza Pública en el sitio La Ye, vía Tibú (Rodríguez, 2017).

\begin{abstract}
Desde las reuniones posteriores al paro, se pensó en no volver a repetir lo sucedido con el paro, ya que no se tenía una organización sólida en cuanto a la movilización; de esta forma, se gestiona por parte de las comunidades campesinas la constituyente regional del Catatumbo "Construimos Mandato para la Paz y el Territorio”, el 5 y 6 de diciembre de 2014, y es allí donde se da la creación de la Guardia Campesina (Téllez, 2018).
\end{abstract}

Como se puede apreciar, la creación de la Guardia se articula no solamente con la salvaguarda de la vida a través de los derechos humanos, como lo mencionan Delgado (2019) y ABColombia (2016), sino que se extiende a un concepto ampliado, en donde este se encuentra ligado al ambiente, al territorio y a la capacidad de decisión que tienen las comunidades para definir y auto determinar su futuro.

Figura 3. Acompañamiento de la guardia a organizaciones campesinas y lideres sociales en realización de denuncias de amenazas, 2017, municipio del Tarra.

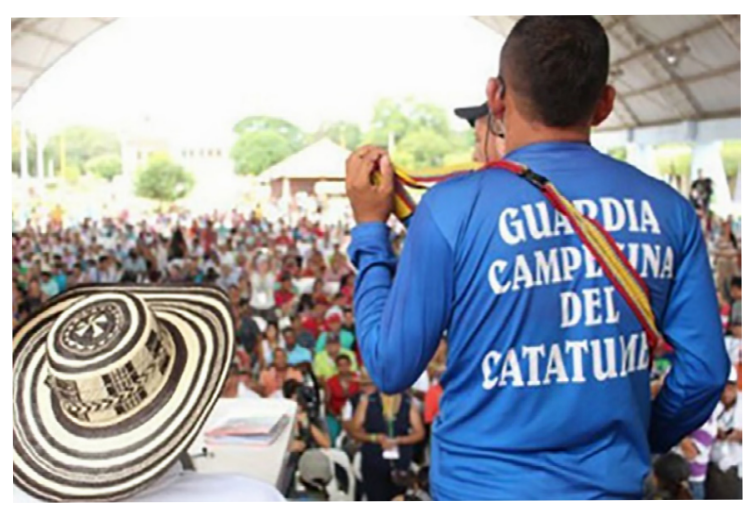

Fuente: ASCAMCAT.

La Guardia Campesina, es una herramienta que no solo defiende la vida de los habitantes del Catatumbo, también se encarga de llevar varias acciones, como la defensa del territorio, ayudas humanitarias, formación en derechos humanos. (Téllez, 2018) 


\section{Autoprotección}

La Guardia Campesina responde a las condiciones territoriales de la región. Dichas condiciones parten del abandono estatal, la ocupación del territorio por actores externos y la violencia ligada al conflicto político militar que han obligado al campesinado a organizarse. La Guardia recoge elementos de identidad campesina que permiten unificar y generar consensos desde lo simbólico y lo inmaterial para llegar a la apropiación de lo material.

Figura 4. Resistencia de la guardia campesina en defensa de lo pactado en la Mesa de Interlocución y Acuerdo MIA-C, 2018.

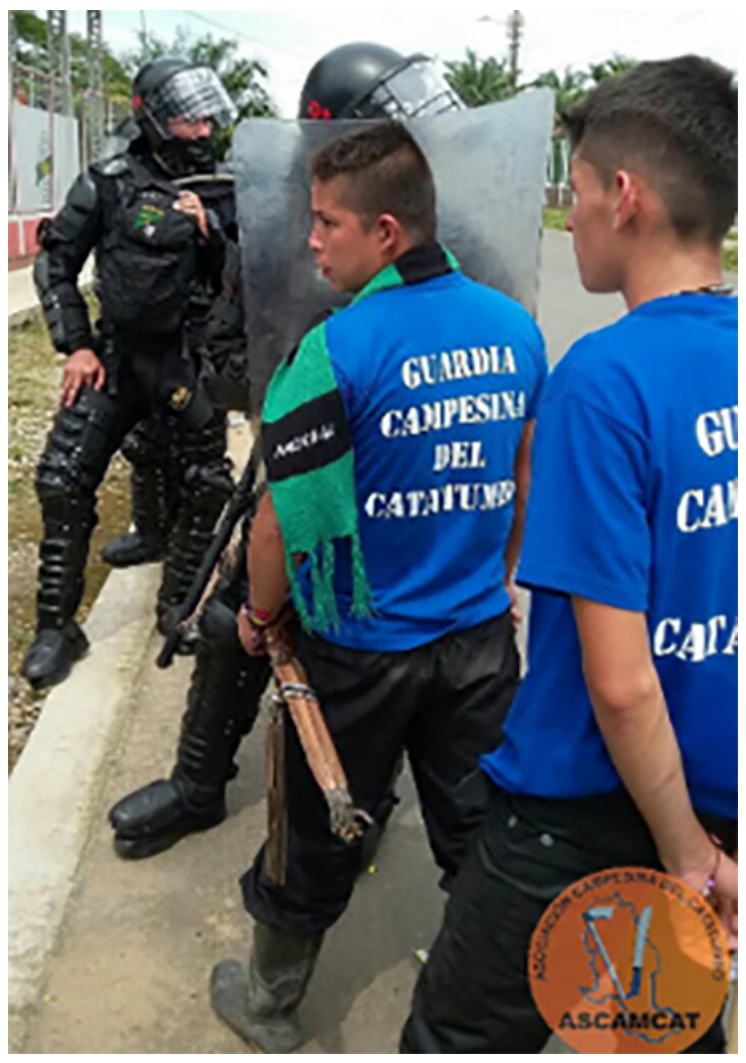

Fuente: ASCAMCAT.

Los mecanismos de autoprotección están unidos a factores de movimiento social y procesos de identidad, esto se puede apreciar en cómo el bolillo que en un comienzo daba el nombre de "bolilleros" a los cultivadores de coca que se enfrentaban a los erradicadores, una vez conformada la Guardia toma el nombre de "bolillo patriótico", con el color de la bandera de Colombia, cuatro nudos que significan los cuatro muertos del paro del año 2013, y una camiseta azul, que simboliza la grandeza del campesino; además, se lleva una machetilla pequeña que encarna la esencia del campesino. (Pabón, 2018)

En lo que tiene que ver con la organización de la Guardia como mecanismo de autoprotección, tiene una estructura organizativa que está direccionada por la directiva de la ASCAMCAT, además se tienen unas coordinaciones que van por zonas: Catatumbo alto, medio y bajo. Si alguien quiere hacer parte de la Guardia, en primera instancia debe pertenecer a una JAC y estar afiliado a ASCAMCAT, además debe ser una persona ejemplar en la comunidad, debido a que el guardia es un mediador en muchos problemas que ocurren en el territorio (Téllez, 2018).

En la Guardia participan hombres y mujeres, y sus acciones van desde ayudar a las comunidades en catástrofes ambientales y olas invernales hasta acompañar los refugios humanitarios, las caravanas que van entrando a la región, los defensores de derechos humanos y funcionarios públicos. También participan niños y niñas (desde los 14 años), con el objetivo de que vayan entendiendo la importancia de la defensa del territorio, a ellos se les denomina Los pioneritos (Abril, 2018). Estas acciones demuestran que la Guardia no es solamente un mecanismo de autoprotección, sino que interactúa con las comunidades campesinas con miras a un ordenamiento e identidad territorial.

Dentro de las acciones de autoprotección, se cuentan procesos de formación en escuelas en materia de derechos humanos, derecho internacional humanitario y en habilidades de interlocución con agentes del Estado (Quesada, 2018). De la misma manera, se tocan temas sobre explotaciones de recursos naturales, primeros auxilios, medio ambiente, así como el tema de género e inclusión a minorías. Esto deja ver un carácter progresista de la guardia (Jaimes, 2018).

VerdadAbierta.com, en el año 2017, estuvo presente en un curso de formación de la Guardia Campesina en una finca del corregimiento Las Juntas, a hora y media en carro del municipio de Hacarí, corazón del Catatumbo, respecto a lo cual señaló lo siguiente: "La Guardia Campesina del Catatumbo se prepara continuamente para ejercer con diligencia funciones de control y protección de su territorio, su única arma es el bolillo patriótico".

Una de las mayores limitantes de la organización se centra en la parte económica, esto ha hecho que los guardias deban conseguir sus implementos de manera autónoma sin 
financiamiento de ningún tipo (Téllez, 2018). Esto desmiente la relación con alguna organización externa y deja ver la capacidad del campesino y su sentido de pertenencia frente al territorio.

La Guardia se mueve a través de la autogestión con eventos para generar recursos y que hacen muchas veces los mismos guardias para comprar su camiseta, bolillo o asistir a los cursos de formación (Abril, 2018).

Figura 5. Recorrido entre campesinos e indigenas para identificar sitios de importancia Barí en el polígono sur de la propuesta de ZRC, 2018.

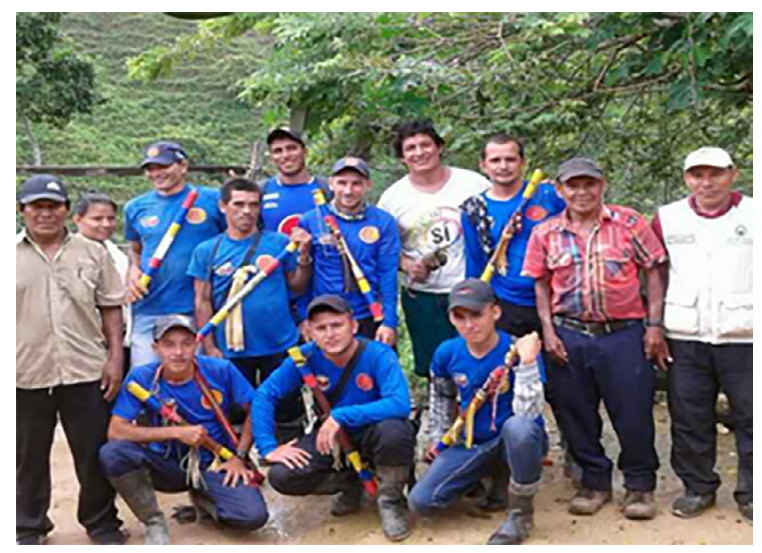

Fuente: elaboración propia.

\section{Empoderamiento y configuraciones territoriales}

El empoderamiento es un proceso de creación $\mathrm{y}$ fortalecimiento de condiciones materiales y subjetivas, personales y colectivas, que posibilitan la participación en la toma de decisiones, acceso y control de recursos por parte de los grupos sociales más vulnerables y la toma de conciencia de su poder individual y colectivo (Souza, 2007).

La Guardia Campesina como mecanismo de autoprotección ha repercutido en el empoderamiento del territorio a través de su defensa en acciones concretas como las movilizaciones campesinas, en respaldo a la toma de decisiones frente al ordenamiento territorial propuesto en la Zona de Reserva Campesina del Catatumbo. La Guardia entonces es una forma de blindaje que trasciende las garantías de derechos humanos y se adentra en ámbitos como la organización del territorio, frenando o haciendo frente a los intereses exógenos y endógenos.

Los campesinos que integran la Guardia tienen la formación frente a las amenazas del Catatumbo; tienen todo el conocimiento de cómo pueden intervenir ante una multinacional, saben cómo salvaguardar el territorio y que se respete en cierta manera el medio ambiente en la región del Catatumbo. Esto se hace por lo general a través de la movilización, interlocución con las empresas, diálogos con operarios o trabajadores encargados de llevar a cabo el trabajo técnico y en algunas ocasiones expulsión del territorio de técnicos y empleados de diferentes empresas (Abril, 2018).

En la actualidad hay amenazas de exploraciones petroleras, carboneras, agroindustriales y maderables, entre otras. Alrededor de 80 a 100 guardias están en vigilancia constante en el territorio. En caso de que se identifique a personas de empresas haciendo estudios o entrando al territorio, los guardias son los encargados de informar a la comunidad y realizar acciones como preguntar las intenciones que existen detrás de los estudios (Pabón, 2018).

La Guardia, en tanto que responde a medidas de autoprotección que se manifiesta en el empoderamiento del territorio, mantiene la directriz de no confrontación sino de interlocución con actores legales e ilegales y autocontrol en momentos de tensión (Abril, 2018). De esta manera, la construcción de paz es una acción que genera configuraciones territoriales, en la medida en que es una respuesta a los actores violentos (ver figura 4 en los Anexos).

El empoderamiento territorial se evidencia en los reconocimientos que se le han hecho a la Guardia por su labor en defensa del territorio, es así como instituciones como "La Defensoría Regional de Ocaña reconoce la guardia como un ejercicio en la autonomía campesina y valora sus procesos de interlocución con el Estado frente a temas como los derechos de las comunidades y el territorio" (Navarro, 2018).

La propuesta de zona de Reserva Campesina del Catatumbo ZRC-C, del año 2012, en el marco de la Ley 160 de 1994, es parte del empoderamiento y organización territorial de la región por parte de los campesinos y en donde la Guardia Campesina ha jugado un papel fundamental en su defensa, a través de las movilizaciones frente amenazas extractivistas.

La Zona de Reserva Campesina está en sintonía con el giro ecoterritorial, que plantea Svampa (2018), al concebir los bienes naturales como bienes comunes, y se matricula en la lucha pro defensa del territorio ante la expansión del proceso de mercantilización. Tiende a focalizarse en la defensa de los bienes naturales, evitar el acaparamiento de tierras, y la sobreexplotación de 
la naturaleza. Por otro lado, también plantea una mirada diferente sobre las relaciones sociales, a partir de la importancia que adquieren los espacios y formas de cooperación social, de uso y goce común (Svampa, 2018).

Hay que señalar que en las respuestas de la Guardia Campesina en defensa del territorio y respaldando la propuesta de ordenamiento territorial, las acciones son de carácter pacifista, centradas en interlocución, derechos humanos, garantías de la protesta social, y en respuesta a acciones de violencia por parte de los actores armados y económicos. Estas acciones "representan empoderamientos pacifistas, expresiones de paces imperfectas y alternativas significativas para la construcción de la paz en Colombia" (Delgado, 2009 , p. 124), ligadas siempre a la protección y configuraciones del territorio, como lo analiza Esperanza Hernández en sus trabajos frente a resistencia de las comunidades rurales, citando experiencias como las de la Guardia.

Los empoderamientos territoriales, las respuestas organizativas a acciones violentas de intereses económicos y las propuestas de organización territorial, desvirtúan las cadenas discursivas propias de los imaginarios de la cultura tecnocrática y política, que han construido una visión de las sociedades campesinas en donde no se les reconoce como sujeto social e inhiben la efectividad de políticas de redistribución al no asignarles capacidades propias para el desarrollo (Salgado, 2002).

\section{Estigmatización institucional y lucha por el reconocimiento}

La Guardia Campesina parte de un contexto con un nivel de exposición y riesgo alto; sin embargo, como se ha mencionado, la Guardia no es una respuesta bélica sino una estrategia para garantizar la protección y una respuesta temprana frente a un riesgo. Esto contrasta con el desconocimiento por parte de instituciones del Gobierno, donde se le ha estigmatizado como una estructura militar paralela a las insurgencias (Jaimes, 2018).

A nivel de historia nacional, los derechos del campesinado han estado relegados a un segundo plano; no obstante, en la actualidad y producto de las luchas en el Catatumbo, se ha logrado generar unos avances en materia jurídica. ${ }^{1}$ Ejemplo de esto es la sentencia T-052 de 2017, que ordena la creación de una mesa consultiva para elaborar medidas de desarrollo alternativo en los territorios en donde confluyen comunidades campesinas con la propuesta de la ZRC e indígenas del Catatumbo, quienes plantean la ampliación del resguardo.

Figura 6. Municipios del Catatumbo.
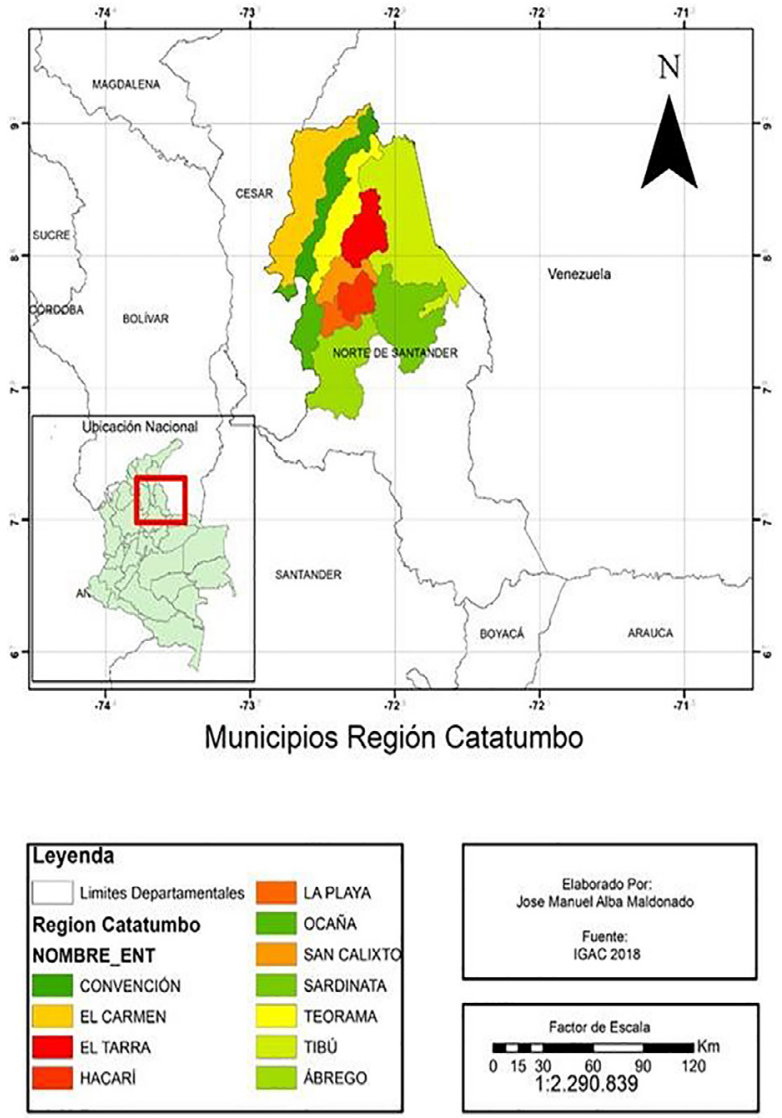

Fuente: elaboración propia.

Estos procesos de lucha por el reconocimiento parten de acciones de formación política, capacitaciones que redundan en mecanismos de autoprotección como la Guardia Campesina, y en propuestas concretas como la Zona de Reserva Campesina, demostrando capacidades en torno al empoderamiento y ordenamiento del territorio que parten de la mirada de sus habitantes, centrada en economías campesinas, defensa de los recursos naturales y control del latifundio.

Respecto al conflicto armado, a la fecha no se han reportado amenazas a miembros de la Guardia, pero sí se han hecho señalamientos en su conjunto, originando estigmatización al cuerpo organizado. Se les ha acusado de constituir una extensión de la estructura armada de las guerrillas, esto ha entorpecido su calidad de garantes frente a las protecciones de las comunidades y del territorio (Jaimes, 2018).

${ }^{1}$ En el plano internacional encontramos la "Declaración sobre los derechos de los campesinos y de otras personas que trabajan en las zonas rurales" (ONU, 2013). 
La estigmatización principalmente ha venido por algunos miembros de la fuerza pública y algunos medios de comunicación (Wilmer Téllez, coordinador de la Guardia Campesina, Vereda Caracol municipio de San Calixto, 10 de agosto de 2018). "Nos relacionan con grupos subversivos, pero al día de hoy no se han registrado asesinatos, solamente los cuatro compañeros asesinados en el paro del año 2013 que pertenecían a los bolilleros" (Pabón, 2018).

La Silla Vacía, en un reportaje sobre este territorio, muestra un poco la relación de los medios de comunicación con la estigmatización. En un artículo se señala a la Guardia como cercana a la guerrilla de las FARC y se ponen en entredicho sus acciones en el desarme del Frente 33:

La guardia campesina, una organización que como lo contamos, es dirigida por la Asociación Campesina del Catatumbo, ASCAMCAT, organización que es afín a los postulados políticos de las FARC, quería hacerle calle de honor a la Unidad Frontera del Frente 33 (Silla Santandereana, 2018).

Es interesante cómo una acción que le da la bienvenida a la paz y un respaldo de la organización al proceso de paz, es juzgada de manera ligera por el medio de comunicación. La Guardia como mecanismo de autoprotección afianza su compromiso con la paz en el territorio con estas acciones.

La estigmatización en la que se ha visto inmersa la Guardia está relacionada con procesos de subvaloración de la figura del campesinado en la sociedad, esto ha hecho que se vea al campesino como un sujeto maleable en función de intereses ocultos, y como sujetos incapaces de tener acción y función política. Dentro de esas lógicas, se hace fácil explicarla como una expresión de agenda oculta subversiva, y no como la demanda legitima ante la ausencia del Estado (Quesada, 2018).

En este marco, por ejemplo, se recopilan algunos señalamientos que realizó la Senadora Paloma Valencia frente a ASCAMCAT y la ZRC-C, ligados a la Guardia Campesina:

La senadora lanzó graves señalamientos en contra de Ascamcat, la Asociación Campesina del Valle del Río Cimitarra (ACVC) y de la Asociación Nacional de Zonas de Reserva Campesina (ANZORC), insinuando que estas organizaciones se encuentran infiltradas por las guerrillas... (Semanario Voz, 2018)
Sin embargo, la lucha de años en la organización social, ha permitido que sectores la reconozcan como un mecanismo de autoprotección en el marco legal. En julio del 2018, más de 20 líderes sociales de todo el país recibieron en Bogotá el apoyo del coordinador residente de la ONU en Colombia. Jhoe Sauca, líder nasa del Cauca, manifestando "No somos aliados del terrorismo, ni narcotraficantes. Tenemos callos en las manos y muchas comas por poner en el gran relato nacional de nuestro conflicto... se debe fortalecer la guardia indígena y las guardias campesinas y cimarronas para la defensa del territorio” (El Espectador, 2018).

\section{Futuro y post-acuerdo}

La visión a futuro de la Guardia Campesina está anclada a seguir consolidándose a nivel nacional como un ejemplo de autoprotección y de defensa territorial. En la actualidad, la Guardia ha llevado a varias regiones del país como Cauca, Putumayo y Caquetá, las experiencias del Catatumbo, y ayudado a generar mecanismos de autoprotección en defensa de las comunidades y de las regiones (Pabón, 2018).

Un escenario ideal en el futuro para la Guardia, es ser reconocida y protegida por el Estado, ya que se convierte en una oportunidad para que el campesino sea reconocido como sujeto político con control y autoridad sobre su territorio. Si acciones organizativas como la Guardia no se protegen, se perderá un instrumento referente valioso para la construcción de la paz y de tejido social; la guardia es una semilla que permite reconocer los actores excluidos del ordenamiento jurídico y político de la nación, y al no valorarla se legitiman más los discursos de violencia, ya sea desde el Estado o de los actores armados irregulares (Quesada, 2018).

En este sentido, el gobernador de Norte de Santander, William Villamizar, elegido para el periodo 2015-2019, ante la preocupante situación en el deterioro del orden público en el Catatumbo, pidió analizar la propuesta de autoprotección colectiva: "Cualquier acción que conduzca a disminuir el peligro hacia la comunidad, que contribuya a disminuir la alteración de orden público y que ayude a generar paz se debe estudiar" (Opinión, 2018).

No obstante la lentitud del reconocimiento de la Guardia como forma de blindar el territorio contra la violencia, las amenazas en la región 
y la permanencia del conflicto armado, hacen que aumenten las amenazas de la organización. Los espacios dejados por las FARC en el proceso de reincorporación, fueron ocupados por otras estructuras militares del Ejército de Liberación Nacional (ELN), frente Camilo Torres y Armando Cacua, y el Ejército Popular de Liberación (EPL) con el frente Libardo Mora Toro, quienes tienen un interés en el control territorial sustentados en economías ilegales.

En el 2017 el frente 33 de las FARC dejó las armas y desde enero de 2018, se empezó a sentir una gran tensión en el Catatumbo. Para enero de 2019, la expansión territorial y el control de economías ilegales por parte del EPL, llevaron a disputas por control con la insurgencia del ELN. Las afectaciones contra la sociedad civil según cifras del Consejo Noruego para los Refugiados fueron de unas 17 mil personas en la región (Sánchez, 2018).

La guerra entre las guerrillas del ELN y EPL se debió principalmente a que el Estado no entró en los territorios para garantizar la estabilidad en las regiones. El vacío de poder generado por la reincorporación de las FARC llevó a que los espacios fueran copados por otros actores armados. De esta forma, se aumentaron las estigmatización, amenazas a líderes sociales, desplazamientos y combates.

La coyuntura en el Catatumbo ha repercutido directamente en el accionar de organismos como la Guardia, ya que en territorios donde se agudiza el conflicto armado es más difícil ejercer acciones de movilización y respeto por el territorio. Esto ha dejado a los campesinos en medio de tensiones entre los grupos subversivos, los intereses extractivistas, la arremetida del ejército y el abandono del Estado Social de Derecho.

En lo que tiene que ver con los acuerdos de La Habana, el punto uno plantea La Reforma Rural Integral, la cual se basa en un enfoque de Desarrollo Rural con Enfoque Territorial (DRET) en donde el eje central es el territorio y se reconoce como el espacio en que un grupo humano, a través de su cultura y condiciones económicas, ambientales y políticas, se apropia de él, generando identidad y pertenencia, y que determina el desarrollo individual y colectivo. Es decir, un proceso de construcción social en el que participan diversos actores e intereses (Molina, Camacho y otros, 2017). Sin embargo, pese a que esto fue un punto central en el proceso de acuerdo de paz, para el caso del Catatumbo, no obstante la resistencia de los movimientos sociales y las propuestas como $\mathrm{ZR}$, no se evidencian avances en lo que respecta al derecho de los habitantes sobre su territorio, y por el contrario, se enfilan proyectos de minería y ampliación de monocultivos con enfoque agro-empresarial.

La visita de Iván Duque a Tibú, el 9 de agosto de 2018, dos días después de su posesión, en donde inauguró la planta extractora de palma, es muestra de un distanciamiento con el DRET, al afirmar que este cultivo iba a promover más de 80 mil empleos en la región del Catatumbo. Esto tiene implicaciones en el reconocimiento de los derechos campesinos, la ZRC y en consecuencia, el reconocimiento a la existencia de una guardia campesina (Jaimes, 2018).

Pese al panorama, la Guardia sigue cumpliendo la función de garante y observador de seguridad para poder prevenir riesgos frente a una situación del contexto del conflicto armado, y respondiendo a la autoprotección y defensa del territorio: "Como guardia seguiremos estando en el Catatumbo respondiendo a las necesidades en torno a la vulnerabilidad que sufren las comunidades en el marco del conflicto armado, aunque nos cueste la vida” (Pabón, 2018).

\section{Conclusiones}

El Catatumbo ha vivido con alta intensidad de conflictividades a lo largo del siglo $\mathrm{XX}$, que se remontan a la colonización petrolera, campesina, llegada de las insurgencias y el conflicto armado, arremetida del paramilitarismo, cultivos ilícitos, desplazamiento, y presencia diferencial del Estado centrada en ejército y policía. Esto ha llevado a que las comunidades realicen procesos organizativos en su región como medidas de autoprotección, que les puedan garantizar no solo el derecho a la vida sino también el acceso al territorio, la permanencia en él y su ordenamiento.

El surgimiento de la Guardia Campesina está enmarcado en el paro del 2013 como un mandato popular de los campesinos del Catatumbo dentro del proceso organizativo de ASCAMCAT. Tiene como objetivo generar un mecanismo de autoprotección que salvaguarde la vida de las comunidades, ligado a la defensa del territorio (escenario de cultura, memoria, espiritualidad, etc.), que repercute en su empoderamiento y organización con miras a la construcción de paz. 
La construcción de la paz, como la entiende Esperanza Hernández, se centra en la materialización de la paz, dentro de un proceso a largo plazo en el que participan diversos actores, iniciativas y actividades. Se relaciona esencialmente con la prevención, transformación o regulación de los conflictos, y la atención integral de quienes han padecido o ejercido las violencias (Delgado, 2009). La Guardia Campesina, en este escenario, es parte crucial en la construcción de paz en el Catatumbo, toda vez que es un actor protagónico en el territorio, con iniciativas y actividades concretas, cuyo objetivo es prevenir y transformar el territorio desde la autoprotección.

Además de esto, la Guardia acude a la identidad campesina, y a la simbología para construir procesos unitarios y consensos entre los campesinos, acudiendo a los valores inmateriales del territorio (cultura, identidad con el territorio, memoria), para la defensa material del mismo. Es decir que la identidad se entrelaza con el territorio y se configura como un mecanismo de defensa, esto debido a que "El territorio representa la vida social, económica y política, no solo para la población existente, sino también para las generaciones futuras. Cuidar y salvaguardar la biodiversidad de su territorio se entrelaza con su punto de vista cultural" (ABColombia, Aid, Oxfam, SCIAF y Trócaire, 2016).

Otro factor importante frente a las conclusiones de la investigación, se centró en evidenciar cómo el campesinado demuestra la capacidad de organizarse y los campesinos se autoreconocen como sujetos políticos, con determinación de decisiones sobre su tierra y con lógicas culturales que pueden dar respuesta a las dificultades que se presentan en diferentes coyunturas políticas, sociales, militares o económicas. Esto redunda en un apoderamiento sobre el territorio que habita, y sobrepasa las estigmatizaciones de las que son víctimas, al considerar la Guardia como un instrumento de las guerrillas que operan en la zona.

En conclusión, se puede decir que la Guardia Campesina del Catatumbo es un mecanismo de autoprotección de las comunidades campesinas, y que esta se muestra como una manifestación del empoderamiento territorial que tienen los campesinos y repercute en las configuraciones y ordenamiento territorial de la región del Catatumbo. La Guardia es una respuesta a la ausencia diferencial del Estado, a las amenazas constantes del conflicto armado, desplazamientos masivos, intereses económicos ligados a las explotaciones de recursos naturales, entre otros fenómenos.

\section{Referencias}

ABColombia, Christian Aid, Oxfam, SCIAF y Trócaire. (2016). Mecanismos de Autoprotección: Comunidades Rurales y Defensores de Derechos $\mathrm{Hu}$ manos en Colombia. Bogotá: ABColombia.

Abril, Y. (2018, 23 de mayo). Entrevista de J. M. Alba. Diario de campo fuente propia.

ASCAMCAT. (2013, 27 de junio). Se instaló la Mesa de Interlocución y Acuerdo (MIA) del Catatumbo. Recuperado de https://prensarural.org/spip/spip. php?article11224

ASCAMCAT. (2013, 29 de noviembre). Detenidos campesinos y posteriormente presentados como guerrilleros en el Catatumbo. Recuperado el 23 de febrero de 2020 de https://www.prensarural.org/spip/ spip.php?article12754

ASCAMCAT. (2016, 17 de febrero). La Zona de Reserva Campesina del Catatumbo: una iniciativa del campesinado que quiere la paz. Recuperado de https://prensarural.org/spip/spip.php?article18687

ASCAMCAT. (2016, 11 de marzo). Guardia campesina en el Catatumbo defiende el territorio. Recuperado de https://prensarural.org/spip/spip.php?article18850

ASCAMCAT e INCODER. (2012). Plan de Desarrollo de la Zona de Reserva Campesina del Catatumbo. Cúcuta: Colectivo de Abogados Luis Carlos Pérez.

Avellaneda, A. (1998). Petróleo, colonización y medio ambiente en Colombia. Bogotá: Ecoe Ediciones.

Caracol Radio. (2013, 27 de diciembre). El paro del Catatumbo marcó en 2013 a Norte de Santander. Recuperado el 23 de febrero de 2020 de https://caracol.com.co/radio/2013/12/23/regional/1387801920_042798.html

Delgado, E. H. (2002). La paz y la no violencia adquieren significado propio en Colombia. ,Reflexión Política, 4 (8), 106-116.

Delgado, M. O. (2003). Debates sobre el espacio en la geografía contemporánea. Bogotá: Editorial UN.

Delgado, E. H. (2009). Paces desde abajo en Colombia. Reflexión Política, 11(22), 176-186.

Delgado, E. H. (2009). Resistencias para la paz en Colombia. Experiencias Indígenas, Afrodescendientes y Campesinas. Revista de Paz y Conflictos, 12 (2), 117-135.

El Espectador. (2018, 22 de abril). La labor de lider social no puede ser estigmatizada. Recuperado de 
https://colombia2020.elespectador.com/pais/la-labor-delider-social-no-puede-ser-estigmatizada

Escobar, A. (2011). Una minga para el posdesarrollo. Signo y Pensamiento 58 . Puntos de vista, $(\mathrm{XXX})$, 30 (58), 306-312.

Forero, J. (2010). Economía campesina, pobreza, tierra y desplazamiento en Colombia. En: El campesino colombiano. Bogotá: Pontificia Universidad Javeriana.

Jaimes, F. R. (2018, 19 de junio). Entrevista de J. M. Alba. Diario de campo fuente propia.

Kroeber. A.L. (1948). Anthtopology. Nueva York: Harcourt Bracero.

La Opinión. (2018, 8 de octubre). Gobernador no descarta idea de protección colectiva. Recuperado de https://www.laopinion.com.co/region/ gobernador-no-descarta-idea-de-proteccion-colectiva-163537\#OP

La Opinión. (2019, 18 de septiembre). Constituirán zona de reserva campesina en el Catatumbo. Recuperado el 23 de febrero de 2020 de https://www. laopinion.com.co/economia/constituiran-zona-de-reserva-campesina-en-el-catatumbo-183954\#OP

Machado, A. (2017). El problema de la tierra. Conflicto y desarrollo en Colombia. Bogotá: Debate.

Mancano, F. B. (2009). Territorios, teoría y política. En C. León, Las configuraciones de los territorios rurales en el siglo XXI (pp. 35-66.). Bogotá: Pontificia Universidad Javeriana.

Mancano, F. B. (2010). Territorio, Teoría y Política. San Pablo: Clacso.

Mesa, C. G. (2010). Derechos Ambientales en perspectiva de Integralidad: Concepto y fundamentación de nuevas demandas y resistencias actuales "Estado ambiente de derechos". Bogotá: Universidad Nacional de Colombia.

Ministerio de Agricultura. (2016). El desarrollo rural en cifras. Bogotá: Ministerio de Agricultura y Desarollo Rural.

Molina, J., Camacho, Y., y Otros. (2017). Formulación de un plan de desarrollo rural con enfoque territorial PEDET. En F. Leiva, Territorio en Vilo. Desarrollo rural para el posconflicto (pp. 43-64). Bogotá: Universidad Nacional de Colombia.

Navarro, R. (2018, 13 de diciembre). Entrevista de V. J. Santiago. Diario de campo fuente propia.

Ortiz Valencia, H. (2013). Concepto del campesino y su resignificación desde la protesta. Perspectivas Rurales, 13 (26), 23-37.

Pabón, E. (2018, 12 de octubre). Entrevista de E. J. Garzón. Diario de campo fuente propia.

PNUD. (2014). Catatumbo: análisis de conflictividades y construcción de paz. Bogotá, D.C: Embajada de Suiza.

Quesada. C. (2013). Derecho a la Consulta Previa para Comu- nidades Campesinas. Bogotá: Universidad Nacional de Colombia, Facultad de Derecho y Ciencias Políticas y Sociales.

Guesada. C. (2018, 28 de noviembre). Entrevista de J. M. Alba. Diario de campo fuente propia.

Réyes Bohórquez, A. (2011). Las zonas de reserva campesina como figuras para el desarrollo rural colombiano. Perspectivas Rurales, 109-120. 11(22).

Rodríguez, E. C. (2017). La protesta campesina en el Catatumbo Colombia (2013). Un análisis sociopolítico. Mundo Agrario, 18 (39), 1-23.

Salgado, C. (2002). Los campesinos imaginados. Bogotá: ILSA. Sánchez Otero, M. (2012). Diagnóstico estratégico de las Juntas de Acción Comunal. Económicas. CUC, 65-80. 33 (1).

Sánchez, N. (2018, 22 de marzo). ¿Qué hay detrás de la guerra entre el ELN y el EPL en el Catatumbo? Recuperado el 22 de enero de 2019 de https:// www.elespectador.com/colombia2020/pais/que-hay-detrasde-la-guerra-entre-el-eln-y-el-epl-en-el-catatumbo-articu$\underline{\text { lo- } 856450}$

Semanario Voz. (2018, 12 de noviembre). Zonas de reserva campesina: ¿Control político o diatriba desatinada? Recuperado de http://semanariovoz.com/zonas-de-reserva-campesina-control-politico-o-diatriba-desatinada/

Sevilla y González. (2004). Seminario sobre el Campesinado. Evolución del concepto de campesino en el pensamiento socialista. Un aporte para la vía campesina. Evolución del concepto de campesino en el pensamiento socialista. Un aporte para la vía campesina (p. 28). Brasilia: MAPA.

Shanin, T. (1979, 29 de noviembre). Campesinos y sociedades campesinas. En T. Shanin, El campesinado como factor político (p. 29). FCE: El Trimestre Económico.

Silla Santandereana. (2018, 23 de octubre). Silla Santandereana. Recuperado de https://lasillavacia.com/ historia/las-guardias-campesinas-se-abren-camino-con-elaterrizaje-de-la-paz-59183

Silla Santandereana. (2018, 26 de marzo). Silla Santandereana. Recuperado de https://lasillavacia.com/historia/ el-detras-de-camaras-de-la-concentracion-de-las-farc-enel-catatumbo-59645

Souza, F. C. (2007). Empoderamiento y sostenibilidad en el desarrollo rural: Trampas de la racionalidad productivista. Revista Andaluza de Ciencias Sociales, 91-104. 7.

Svampa, M. (2018). Las fronteras del neoextractivismo en América Latina. Guadalajara: CALAS.

Téllez, W. (2018, 10 de agosto). Entrevista de M. J. Alba. Diario de campo fuente propia.

Valdés Correa, B. (2018, 19 de octubre). El Catatumbo resiste y renace, pero necesita un Estado presente. El Espectador. Recuperado de https:// 
www.elespectador.com/colombia2020/justicia/verdad/ el-catatumbo-resiste-y-renace-pero-necesita-un-estado-presente-articulo- 857258

Verdad Abierta. (2018, 8 de junio). En la escuela Guardia Campesina del Catatumbo se forman los defensores del territorio. Recuperado de https:// verdadabierta.com/en-la-escuela-guardia-campesina-del-catatumbo-se-forman-los-defensores-del-territoriol 